\title{
Principles of OCTA and Applications in Clinical Neurology
}

\author{
Adam Wylęgała $^{1,2}$ \\ Published online: 18 October 2018 \\ (C) The Author(s) 2018
}

\begin{abstract}
Purpose of Review The article reviews the recent findings on the use of optical coherence tomography angiography (OCTA) in neurology.

Recent Findings OCTA is a new addition to the powerful and complementary technology of the OCT. Due to its noninvasiveness, and reproducibility, it is possible to obtain high-resolution 3D images of the vessels of the human eye. As the vessels of the retina with the presence of endothelial cell's tight junctions resemble the brain vessels, it was hypothesized that the imaging of the retinal vessels might bring insight into brain vessels. OCTA has been effectively used to predict retinal vessel abnormalities in dementia, demyelization, optic disc neuropathies, and inherited degenerative diseases. Most common findings were decrease of vascular density and flow and an increase of avascular zones.

Summary Although OCTA is a relative new technology, recent studies show that it can be successfully applied in neurology.
\end{abstract}

Keywords OCT angiography $\cdot$ OCTA review $\cdot$ Sclerosis multiplex $\cdot$ Neuroscience $\cdot$ OCT-A $\cdot$ Optical coherence tomography angiography,

\section{Introduction}

The ability of ophthalmologists to detect blood vessels of the fundus was always seen as a great advantage. For over 100 years, various machines to determine blood flow and to visualize blood vessels have been developed. They have differed in their degree of precision, invasiveness, and patient safety [1]. The introduction of optical coherence tomography (OCT) is seen as one of the most fundamental milestones in the history of ophthalmology. It enables 3D imaging of the structures of the eye, e.g., ganglion cell (GCL), macula, optic disc, or cornea, and can measure the size of the optic discs and the thickness of the retinal layers. The submillimeter resolution is easily obtained in histological sections, and the posterior segment penetration is $>1 \mathrm{~mm}$. OCT uses a light source and an interferometer and algorithms to produce images based

This article is part of the Topical Collection on Neuro-Ophthalmology

Adam Wylęgała

adam.wylegala@gmail.com

1 Ophthalmology Department, Railway Hospital, Katowice Panewnicka 65, 40765 Katowice, Poland

2 II School of Medicine with the Division of Dentistry, Zabrze Medical University of Silesia, Katowice, Poland on the amplitude and the delay of reflected light $[2 \bullet \bullet]$. Currently, there are two different technologies utilized by the OCTA devices-spectral domain (SD-OCT) and swept source (SS-OCT). The latter technology is faster and, as it uses longer wavelengths, it provides higher penetration. Moreover, some studies have shown that SS-OCTA has higher sensitivity than SD-OCT $[3,4]$.

Since 2006, a new software called OCT angiography (OCTA) has been added to OCT devices to enable noninvasive visualization of blood flow. Although it took almost a decade to get this technology on the market [5], OCTA is a useful technology in detection of retinal diseases such as choroidal neovascularization [6], macular malformations in telangiectasias [7], capillary dropouts in diabetic retinopathy [8], perfusion loss in vessels occlusions [7], and changes in flow around the optic disc in glaucoma [9]. In addition to the high reproducibility and repeatability of foveal avascular zone (FAZ) measurements and blood flow in healthy and multiple sclerosis (MS) patients, respectively $[2 \cdot \bullet, 10,11]$, the capillary changes in OCTA are also shown to correlate with that of perimetry [12]. The presence of tight endothelial cell junctions in the blood-retinal barrier resembles that of the blood-brain barrier. Although the retinal circulation resembles that of a brain, it lacks autonomic control [13, 14]. As CNS and retinal arterioles share the same embryology and histology [15], measuring the structure and flow within the retinal vessels offers 
the promise of an objective quantitative and noninvasive technique that in theory corresponds with brain vessel architecture.

At present, we understand that the retinal blood supply is organized into four vascular plexuses. The central retinal artery supplies blood to the superficial capillary plexus (SCP), which then anastomoses and creates the intermediate (ICP) and deep capillary plexuses (DCPs). The SCPs are located within the retinal nerve fiber layer (RNFL), ganglion, and inner plexiform layers. While the DCPs are located below, the ICP are located above the inner nuclear layer [14]. Blood vessels are not present in photoreceptors and outer plexiform layers. The fourth retinal plexus is called radial peripapillary capillary plexus (RPC) and runs parallel with the nerve fiber layer axons. RPC contrary to the DCP does not have lobular configuration [1]. Right now, OCTA, as it is coregistered with OCT B-scan, is seen as a method capable to replace fluorescein angiography (FA) in most cases of the retinal and choroidal neovascularizations (Fig. 1). FA is a dye-based technology which visualizes only the SCP due to the blockade of fluorescein from the deeper retinal layers. However, OCTA enables detection of retinal vessels in desired layer [14]. To understand this, let us imagine the difference between a telescope located on earth that offers the astronomer only limited insight into space due to blockage of UV light coming from earth's atmosphere and a telescope in the outer space with unblocked insight into other galaxies in all light spectrums [16].

\section{How Does It Work?}

OCTA works by collecting multiple cross-sectional scans (Bscans) of the same location and then detecting the differences in motion contrast, amplitude, intensity, or phase. The methods used depend on a particular device. Since motionless objects do not produce any change in a signal contrary to moving objects and the retina and choroid are stationary tissues, the differences in values are believed to be coming from the only moving particle within them which is blood. Erythrocytes, due to their biconcave structure, reflect light.

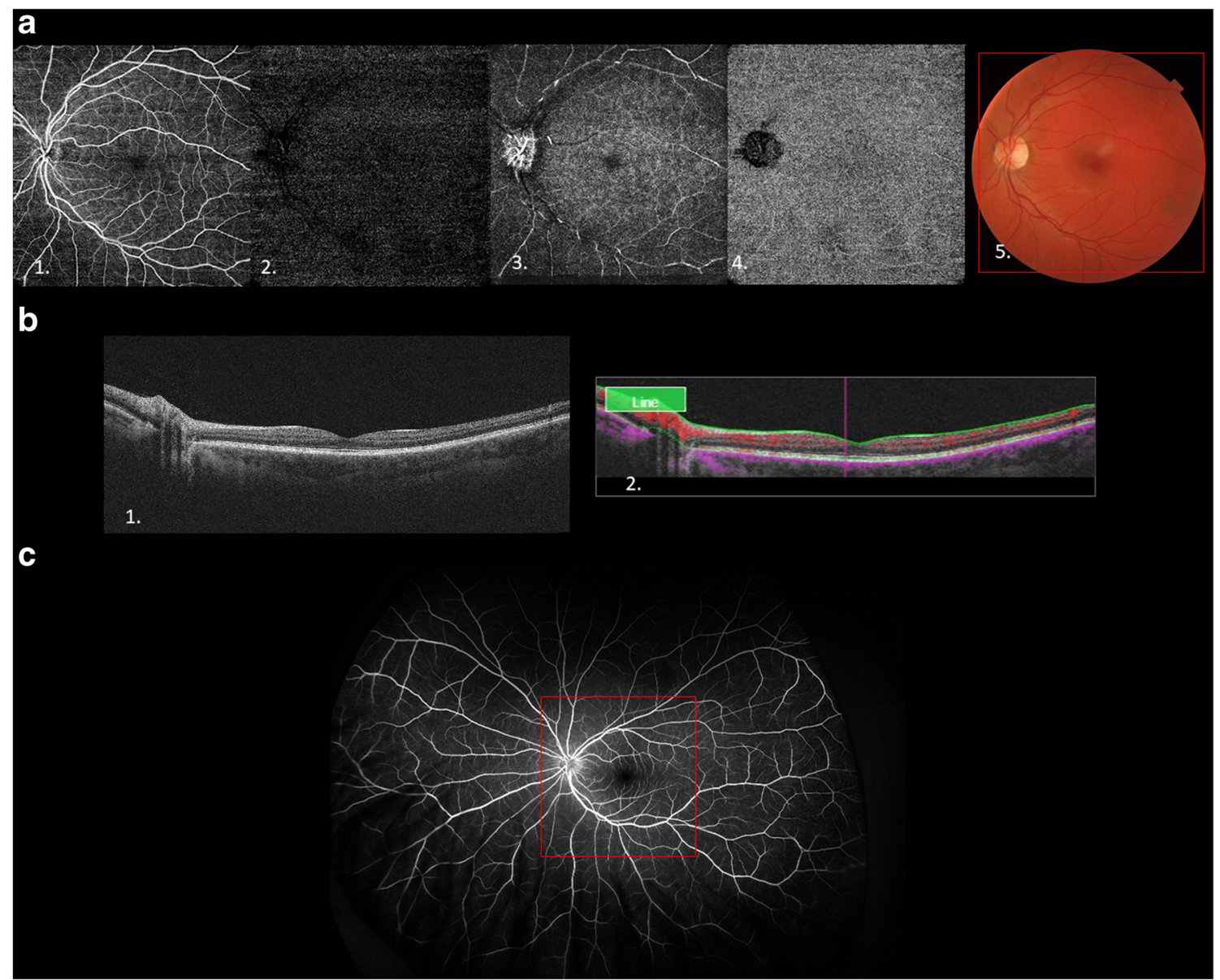

Fig. 1 a Optical coherence angiography of a healthy retina. 1. Scan of a superficial layers. 2. Intermediate retinal plexus. 3. Deep retinal plexus. 4. Choroid. 5. Color fundus photo with a red frame corresponding to the area on an OCTA image. b 1. OCT B-scans of the retina. 2. B-scan with color coded to indicate the blood flow. c Images of an ultra-wide field fluorescein angiography, the size of an OCTA image corresponds to the red frame 
Such scanning is then performed in different axes to create a 3D image $[17,18]$.

\section{What Can Be Measured in OCTA?}

The primary function of this technology is to visualize the architecture of blood vessels without the need to inject the dye. It is important to know that the image that is being created, unlike in FA, is just a result of a mathematical calculation of the computer. This can be useful in calculating various parameters including blood flow [19], vessel density, size of a vascularized and FAZ [20], size of perfusion [21], fractal analysis, or even measurement of complexity of a mathematical tree [22]. Furthermore, the descriptive morphologies of the vessel architecture like diameter, length, or number of branches can also be calculated [22].

\section{Methods}

A literature search was conducted including all articles published up to September 2018. A PubMed, Web of Science, Google Scholar, and Mendeley search with reference cross matching was used to identify all relevant articles pertaining to OCT angiography, dementia, neurology, brain, mild cognitive decline, neuritis, multiple sclerosis, and neuropathy.

\section{Dementia}

Primary risk factors of neurodegenerative disorders are advanced age and cardiovascular disease. With the increase in life expectancy, new methods of screening are needed [23]. At the level of cerebral microvasculature, there is a growing evidence of age-related drop in capillary numbers and density observed in humans [24] and in rodents [25, 26]. Diagnostic methods for detecting and defining neurodegenerative syndrome routinely used by neurologists such as CSF assessment, PET, and MRI are either limited by their invasive nature or high costs [27]. Alzheimer's disease (AD) is considered the most common type of dementia. Common ophthalmologic signs and symptoms of AD are visual field changes and decreased visual acuity [28]. Pathologically, it is characterized by deposition of plaques and tangles that consist of amyloid and tau protein, respectively. It is estimated that retinal microvascular changes such as microaneurysms, soft or hard exudates, retinal hemorrhages, macular edema, intraretinal microvascular abnormalities, venous beading, new vessels, vitreous hemorrhage, or disc swelling are associated with cognitive decline [29]. Moreover, other retinal alterations such as changes in the thicknesses of macular RNFL are associated with early changes in Alzheimer-type dementia [30]. Although other studies showed a decrease in ganglion cell layer (GCL) [31], the changes in RNFL and inner plexiform layer [32] are associated with the neocortical $\mathrm{A} \beta$ accumulation, while GCL is not [33]. A recent study evaluated OCTA findings in AD. The authors described enlarged FAZ measured by the OCTA device and decreased retinal vascular density and choroidal thickness which correlated with a decrease on Mini Mental State Examination. They attribute these changes to decreased angiogenesis caused by binding of vascular endothelial growth factor (VEGF) to A $\beta$ plaques [34•]. In a comparative study on twins, it was observed that a twin with $\mathrm{AD}$ had larger FAZ in SCP and thinner choroid compared with the healthy sibling [35]. Similarly, in a study by Jiang et al., AD patients had reduced density of both SCP and DCP in comparison with controls, whereas patients with mild cognitive impairment had reduced density only in DCP and in the superior nasal quadrant [36]. Thus, as the blood from the central retinal artery supplies firstly SCP and then DCP, reduced SCP density can lead to decreased blood flow through the outer layers of retina which may lead to continual loss of ganglion cell axons [37].

In migraine, mainly peripapillary RNFL thickness is reduced, especially in patients with aura [38]. One study demonstrated reduced parafoveal SCP density and superior RPC density in patients with migraine with aura compared with migraine without aura and healthy controls. Furthermore, patients with aura had enlarged FAZ. However, the authors speculate that this is probably associated with increased risk of retinovascular occlusion, normal tension glaucoma, and ischemic optic neuropathy among patients with migraine. The authors did not observe significant changes between migraine without aura and healthy controls [39•].

The article by Nelis et al. describes changes in OCTA observed in 21 eyes of 11 patients with cerebral autosomal dominant arteriopathy with subcortical infarcts and leukoencephalopathy (CADASIL). The patients showed decreased vessel density in DCP which the authors associate with Notch3 mutation in pericytes. However, only 9 patients included had confirmed Notch3 mutations [15]. Notably, this corresponds to a report of OCT findings by Fang et al. where the inner arterial diameter and arterial to venous ratio of the inner and outer diameters correspond negatively to a number of small infarcts in the 7T MRI [40].

Falavarjani et al. evaluated optic nerve microvasculature in 21 eyes of patients with optic disc edema, pseudoedema, and atrophy and compared them to 12 heathy eyes. They observed decrease in the RPC which was more outstanding in areas with sectorial optic atrophy. The capillaries of the patients with disc edema were dilated and tortuous. The mean capillary density was significantly decreased in eyes with disc atrophy. Moreover, the RPC vessel density correlates with the NFL thickness. The authors hypothesize that reduced metabolic need is caused by reduced number of nerve fibers; however, it had not been the subject of the study [41]. 


\section{Optic Disc Ischemic Neuropathies}

The role of OCTA in detecting vascular optic nerve abnormalities is even more promising. Ischemic injury to the optic disc is a clinical syndrome known as anterior ischemic optic neuropathy (AION). This syndrome can be divided into arteritic (AAION) and non-arteritic (NAION). AAION is a focal manifestation of giant cell arteritis, a systemic inflammatory disorder, and the perfusion defect is located at the level of posterior ciliary artery. In the NAION form, the perfusion defect is at the distal end of the posterior ciliary circulation at the level of paraoptic branches [42]. Fard et al. using OCTA observed a $2.2 \%$ loss of RPC compared with the healthy group [43]. Furthermore, Ling et al. using OCTA showed a $7.23 \%$ increase in the size of nonvascular tissue in 21 eyes compared with the controls' eyes with NAION [44]. Patients with NAION have unilaterally decreased RPC density, whereas glaucomatous patients were bilateral [45]. Moreover, a positive correlation between decrease of RPC, RNFL [46], and GCC [46] was observed. Although, at present, OCTA is not helpful in distinguishing AION from NAION [42], it is reasonable to consider the possibility that the changes located proximal to the division of posterior ciliary arteries into paraoptic and choroidal branches affect RPC in both disorders.

\section{Demyelinating Disease}

Multiple sclerosis (MS) is a chronic demyelinating inflammatory disease. Autopsy revealed that $99 \%$ of patients have had signs of demyelination within the optic nerve [47]. Optic neuritis is a primary manifestation in $25 \%$ of patients and can occur in $50 \%$ of the patients during the course of the disease [48••]. Although several articles concerning OCTA of patients with MS appeared in the literature, one of the earlier studies showed that optic nerve head $(\mathrm{ONH})$ flow measured within the whole optic nerve head with an experimental device in patients with optic neuritis was reduced by $12.5 \%$ compared to controls. Furthermore, the flow index was also lower in patients without optic neuritis compared with controls. Moreover, $21 \%$ of MS patients with correct visual acuity showed abnormal flow [11].

Spain et al. showed reduced ONH perfusion by OCTA in patients with MS, particularly those with a history of optic neuritis. Although combining OCT angiography with other OCT parameters increased the diagnostic accuracy of detecting MS in eyes with optic neuritis, there was no significant correlation among flow index and GCC and RNFL [48••]. They used the same experimental procedure as Wang et al. [11]. One relatively large OCTA study documented that lowered vessel densities in both SCP and DCP in the perifoveal region are correlated with decreased volume of corresponding retinal layers compared with the healthy controls.
Furthermore, there was an increase in choriocapillaries density which the authors linked to the inflammation within the last 24 months [49••].

Overall, the literature indicates that MS leads to decreased retinal ganglion cells and RNFL thickness measured in OCT, which results in lower metabolic activity and rarefication of the vascular plexus. Some authors advocate the presence of autoregulatory mechanism or alterations in endothelium that were observed in MS brains. The authors attribute the lack of changes in the parafoveal regions among the groups to the lack of macular RNFL and the fact that macula is supplied by the choroid and the range of autoregulation is much bigger than for the regions supplied by the retinal vessels [11]. However, they did not differentiated retinal vascular plexus but measured flow index in the whole retina.

Neuromyelitis spectrum disorder (NMOSD) with AQP4$\mathrm{IgG}$ is characterized by the presence of AQP4-IgG and one of the clinical characteristic: optic neuritis, acute myelitis, acute brainstem syndrome, area postrema syndrome, symptomatic cerebral syndrome with NMOSD brain lesions, symptomatic narcolepsy, or acute diencephalic clinical syndrome with NMOSD-typical diencephalic MRI lesions [50]. There are some reports on the functionality of OCTA in NMOSD. A recent study assessed peripapillary and parafoveal vascular network in aquaporin-4 antibody positive NMOSD. The study team evaluated 108 eyes of 67 patients divided into two groups based on the history of optic neuritis. Moreover, 66 eyes of 33 healthy participants were added into study as a control. RPC vessel density was significantly reduced compared with both controls (15.7\%) and non-neuritis patients $(13.5 \%)$. The parafoveal density was decreased to $3.2 \%$ and $5.9 \%$ in neuritis patients compared with non-neuritis patients and controls, respectively. In addition, a positive correlation between OCT parameters which are RNFL, GCL thickness, and OCTA capillary density in both measured regions was observed [51••]. In the retina, the Müller glial cells expressing aquaporin-4 which regulate blood flow [52] and support neurons may be directly targeted by aquaporin-4 antibody [51 ••]; the loss of which may lead to thinning of the retinal layers and reduced vascular density [53]. The authors concluded that vascular changes occur prior to the development of optic neuritis and advocate OCTA as a future tool for detecting subclinical vasculopathy in NMOSD patients without optic neuritis $[51 \bullet \cdot$. Same conclusions were drawn in that the decrease in capillary density of both SCP and DCP observed in OCTA correlates and partially contributes to neuroaxonal thinning of the retina [54].

\section{Optic Pathway Pathologies}

Leber hereditary optic neuropathy (LHON) is a hereditary mitochondriopathy that causes painless vision loss, typically bilateral, that often affects young males. Its signs include 
transient telangiectasia seen in OCTA [55-57], swelling of the RNFL (pseudoedema) in OCT, and absence of leakage in FA $[57,58]$. In a OCTA study of 22 patients with LHON divided into four groups (unaffected carriers of the mitochondrial DNA mutation, symptomatic patients in the early subacute phase, late subacute, and chronic), a significant drop in RPC density (19.06\%) was first observed in the temporal regions of early subacute patients compared with the unaffected carriers. Whereas the late subacute patients had, in general, a decreased temporal RPC density of $24.27 \%$ and a whole RPC density of $8.99 \%$, and chronic patients had a decreased temporal RPC density of $36.09 \%$ and a whole RPC density of $24.65 \%$. While in the chronic patients, decreased whole RPC density was observed, the RPC density of unaffected carriers increased in temporal regions together with RNFL thickness compared with controls. The authors explain this fact by swelling of the axons in both unaffected and acute stage patients as a compensatory aggregation of mitochondria or due to the failure of axonal transport that leads to microangiopathy. As small optic discs are risk factors in LHON, another explanation is that the insufficient vascular supply causes axonal swelling leading to compartment syndrome and to degeneration of ganglion cells [59-61]. Based on the current literature, it is impossible to determine whether the microangiopathy is causing or correlates with the RNFL swelling.

Later, during the course of disease, this swelling turns into atrophy. Secondly, the vascular decrease occurs faster than a decrease in RNFL thickness which the authors attribute to the slower resolution of swelling [60•]. Another OCTA study showed a $9.1 \%$ and $9.4 \%$ decrease in SCP and DCP, respectively, compared to healthy subjects. This study also observed higher decrease in the inferior and temporal regions of the disc where the papillomacular bundle is located. However, in contrary to decrease in SCP that correlates with decrease in visual loss, the authors observed no correlation between the visual loss and OCT structural damages [55].

Another study reported the use of OCTA in patient with a Wolfram syndrome, a rare neurodegenerative disease including diabetes insipidus, diabetes mellitus, deafness, and optic neuropathy. This entity is associated with a defect in transmembrane protein that maintains calcium homeostasis. The OCTA showed reduced vessels in RPC and SCP that corresponded with the OCT-measured RNFL thinning. Morphologically, the vessels were telangiectatic and tortuous. The authors compared the findings with the OCTA results of LHON and dominant optic neuropathy patients and speculate on the possible mitochondrial involvement [62]. Parrozzani et al. advocate that retinal vascular remodeling is a consequence of axonal degeneration.

In an OCTA study on 26 patients with posterior optic pathway gliomas involving the chiasma, retrochiasmal, or both, they observed reduction of macular perfusion in DCP, whereas SCP was not affected by this entity. Furthermore, reduction in OCT-measured RNFL is correlated with the decrease in peripapillary perfusion. Therefore, the authors demonstrated that the decrease of retinal perfusion is secondary to reduction of retinal neurons which leads to reduced metabolism. They suggest a pivotal role of Müller cells in this feedback mechanism [63••].

\section{Discussion}

OCTA opens unique opportunities and already showed great potential in visualizing the blood vessels. Even early studies using fundus photography showed association between retinal vasculature and a risk of stroke [64, 65], or cognitive ability $[66,67]$. OCTA, however, is not free from shortcomings - the biggest being the presence of artifacts coming from the motion of the eye or from the other vessels. Not all light is transmitted from the erythrocytes, e.g., melanosomes of the choroid backscatter light so that the choroidal vessels are imagined dark [68]. Despite constant upgrades in software, the motion artifacts are still limiting the use of the instrument in older patients and children with poor cooperation as they have to fixate their eyes for some time [22]. Moreover, presence of epiretinal lesions such as myelinated fibers may also obscure the images [69]. Studies conducted in animal models show that injecting contrast agents that are more symmetrically shaped than the erythrocytes allows us to observe images with less artifacts as some of the artifacts are inherent to the method of detecting erythrocytes [68].

OCTA is an emerging technology with still many limitations, requiring careful use and interpretation. The literature on the topic is of mediocre quality with mostly small, singlecenter retrospective studies [43-46, 63••, 70-72]. Some authors have calculated parameters based on several instruments which can lead to inaccurate results [43]. Others had to export the images to another program which could also reduce the quality of the results [15]. The changes demonstrated in the articles like enlargement of FAZ or decrease in capillary plexuses density are unspecific and were observed in many other conditions like diabetic retinopathy [73], vessels occlusions [74], or post-surgery [75]. Likewise, there is no body of literature addressing the relation of OCTA-imaged vessels and treatment in neurological research. Last but not least, the manufacturers use different algorithms for detecting retinal motion and segmenting retinal layers making it difficult to compare the results between the studies [17, 76]. In addition, in all studies, only perimacular and papillary regions were assessed. To conclude now, it is not possible to make a diagnosis based on the OCTA images or blood flow.

Calculation of blood flow may lead to better understanding of pathology and facilitate diagnosis of many neuroophthalmic diseases. However, it is still unknown how reliable are the results obtained by the machines because, firstly, the 
algorithms are sensitive to a certain speed - below or above which the flow will not be detected nor the vessels visualized - and, secondly, the accuracy of the flow speed depends on OCT scan quality - images that are out of focus, full of artifacts coming from optical opacities, and motion artifacts will produce false results [77]. Whether flow indexes will enter the clinical practice is also unknown. Another controversy exists whether the observed changes in the retinal vasculature directly reflect the brain microvasculature or are secondary to the vascular risk factors, e.g., aging [76]. A major methodological challenge exists as, at the time of writing this review, the OCTA technology is still under rapid development.

Alternative techniques currently used in vessel visualization:

Currently, a few alternatives exist to OCTA.

Currently, many manufacturers sell OCT devices with OCTA functionality. Moreover, many prototypes [78-80] with much higher speed and penetration are used in research. However, OCTA is not the only technology used in detection of vessels and measuring flow. Adaptive optics is a tool of correcting scanning laser ophthalmoscopy that allows to observe structures as small as single photoreceptors. However, this method is time consuming and produces only small field of view $[1,81,82]$.

While Doppler OCT yields flow in microliter per minute, OCTA can provide date in arbitrary units only; however, it can only be used in larger vessels and perpendicular to the probe [21].

A current gold standard technology - FA with fundus photo - is limited by its $2 \mathrm{D}$ size and its inability to visualize a particular layer as it creates a merged image of only microscopical vessels. FA is associated with some side effects, the most severe, however, very rare being anaphylactic shock. OCTA has also much higher resolution than FA which makes it possible to detect small areas of retinal non-perfusion that can resemble cerebral microinfarctions [83]. Furthermore, there is no need to inject the dye and, hence, the possibility to reproduce the examination as many times as the examiner wants. OCTA is more sensitive than dye-based techniques in detecting small perifoveal capillaries and radial peripapillary capillaries [84]. As it is not dependent on dye reflectance, it can produce more sharp images than FA, in which borders cannot be seen with such contrast due to leakage [85]. However, FA is well established and many diseases have particular features seen only in FA. Therefore, performing FA may be crucial for diagnosis.

\section{Conclusion}

Advancements in noninvasive techniques for measurement blood flow are likely to change many medical fields including neurology. More prospective studies are needed with the use of medications to observe changes in vascular parameters and architectures to validate initial reports. Another field of future studies should be the use of OCTA in stroke, neurodegenerative psychiatric disorders such as schizophrenia, and determination of retinal blood flow in other pathologies like Uhthoff's phenomenon $[86,87]$.

Funding Information This work was financially supported by the National Center for Research and Development Grant No. STRATEGMED1/234,261/2/NCBR/2014.

\section{Compliance with Ethical Standards}

Conflict of Interest Adam Wylegała has a patent interest in the subject of this article. Polish patent office P.418979.

Human and Animal Rights and Informed Consent This article does not contain any studies with human or animal subjects performed by any of the authors.

Open Access This article is distributed under the terms of the Creative Commons Attribution 4.0 International License (http:// creativecommons.org/licenses/by/4.0/), which permits unrestricted use, distribution, and reproduction in any medium, provided you give appropriate credit to the original author(s) and the source, provide a link to the Creative Commons license, and indicate if changes were made.

\section{References}

Papers of particular interest, published recently, have been highlighted as:

- Of importance

•- Of major importance

1. Morgan JIW. The fundus photo has met its match: optical coherence tomography and adaptive optics ophthalmoscopy are here to stay. Ophthalmic Physiol Opt [Internet]. 2016;36:218-39. Available from. https://doi.org/10.1111/opo.12289.

2.• Spaide RF, Fujimoto JG, Waheed NK, Sadda SR, Staurenghi G. Optical coherence tomography angiography [Internet]. Prog. Retin. Eye Res. Pergamon; 2018 [cited 2018 Aug 17]. p. 1-55. Available from: https://www.sciencedirect.com/science/article/pii/ S1350946217300563?via\%3Dihub. Up to this date, the most comprehensive review of OCTA in ophthalmology.

3. Novais EA, Adhi M, Moult EM, Louzada RN, Cole ED, Husvogt $\mathrm{L}$, et al. Choroidal neovascularization analyzed on ultra-high speed swept source optical coherence tomography angiography compared to spectral domain optical coherence tomography angiography. Am J Ophthalmol [Internet]. 2016; Available from: http://linkinghub. elsevier.com/retrieve/pii/S0002939416300447

4. Told R, Ginner L, Hecht A, Sacu S, Leitgeb R, Pollreisz A, et al. Comparative study between a spectral domain and a high-speed single-beam swept source OCTA system for identifying choroidal neovascularization in AMD. Sci Rep [Internet]. Nature Publishing Group; 2016 [cited 2018 Aug 18];6:38132. Available from: http:// www.nature.com/articles/srep38132

5. Makita S, Hong Y, Yamanari M, Yatagai T, Yasuno Y. Optical coherence angiography. Opt Express [Internet]. 2006;14:7821. Available from: https://www.osapublishing.org/oe/abstract.cfm? uri=oe-14-17-7821 
6. Roisman L, Goldhardt R. OCT angiography: an upcoming noninvasive tool for diagnosis of age-related macular degeneration. Curr Ophthalmol Rep [Internet]. 2017 [cited 2018 Aug 17];5:136-40. Available from: http://www.ncbi.nlm.nih.gov/pubmed/29051844.

7. Suzuki N, Hirano Y, Yoshida M, Tomiyasu T, Uemura A, Yasukawa T, et al. Microvascular abnormalities on optical coherence tomography angiography in macular edema associated with branch retinal vein occlusion. Am J Ophthalmol [Internet]. Elsevier Inc.; 2015;161:126-132.e1. Available from: http://linkinghub. elsevier.com/retrieve/pii/S000293941500608X

8. Schaal KB, Munk MR, Wyssmueller I, Berger LE, Zinkernagel MS, Wolf S. Vascular abnormalities in diabetic retinopathy assessed with swept-source optical coherence tomography angiography widefield imaging. Retina [Internet]. 2017 [cited 2018 Aug 17];1. Available from: http://www.ncbi.nlm.nih.gov/pubmed/29135803.

9. Igarashi R, Ochiai S, Sakaue Y, Suetake A, Iikawa R, Togano T, et al. Optical coherence tomography angiography of the peripapillary capillaries in primary open-angle and normal-tension glaucoma. Bhattacharya S, editor. PLoS One [Internet]. Public Library of Science; 2017 [cited 2018 Aug 17];12:1-12. Available from: https://doi.org/10.1371/journal.pone.0184301

10. Carpineto P, Mastropasqua R, Marchini G, Toto L, Di Nicola M, Di Antonio L. Reproducibility and repeatability of foveal avascular zone measurements in healthy subjects by optical coherence tomography angiography. Br J Ophthalmol [Internet]. 2015;100:1-6. Available from. https://doi.org/10.1136/bjophthalmol-2015307330.

11. Wang X, Jia Y, Spain R, Potsaid B, Liu JJ, Baumann B, et al. Optical coherence tomography angiography of optic nerve head and parafovea in multiple sclerosis. Br J Ophthalmol [Internet]. 2014;98:1368-73. Available from. https://doi.org/10.1136/ bjophthalmol-2013-304547.

12. Simó R, Stitt AW, Gardner TW. Neurodegeneration in diabetic retinopathy: does it really matter? Diabetologia [Internet]. 2018;61: 1902-12 Available from: http://www.ncbi.nlm.nih.gov/pubmed/ 30030554\%0A http://www.ncbi.nlm.nih.gov/pubmed/30030554.

13. Park M, Kim H-J, Lim B, Wylegala A, Toborek M. Methamphetamine-induced occludin endocytosis is mediated by the Arp $2 / 3$ complex-regulated actin rearrangement. J Biol Chem [Internet]. 2013 [cited 2014 Jul 25];288:33324-34. Available from: http://www.jbc.org/content/early/2013/09/30/jbc.M113. 483487

14. Campbell JP, Zhang M, Hwang TS, Bailey ST, Wilson DJ, Jia Y, et al. Detailed vascular anatomy of the human retina by projectionresolved optical coherence tomography angiography. Sci Rep [Internet] Nat Publ Group. 2017;7:1-11. Available from:. https:// doi.org/10.1038/srep42201.

15. Nelis P, Kleffner I, Burg MC, Clemens CR, Alnawaiseh M, Motte J, Marziniak M, Eter N, Alten F OCT-angiography reveals reduced vessel density in the deep retinal plexus of CADASIL patients. Sci Rep [Internet]. Springer US; 2018;8:8148. Available from: https:// doi.org/10.1038/s41598-018-26475-5

16. Savage BD, Sembach KR. Interstellar abundances from absorptionline observations with the hubble space telescope. Annu Rev Astron Astrophys [Internet]. Annual Reviews 4139 El Camino Way, P.O. Box 10139, Palo Alto, CA 94303-0139, USA; 1996 [cited 2018 Aug 17];34:279-329. Available from: https://doi.org/ 10.1146/annurev.astro.34.1.279

17. Wylegała A, Teper S, Dobrowolski D, Wylegała E. Optical coherence angiography: a review. Medicine (Baltimore) [Internet]. 2016;95:e4907. Available from: http://www.ncbi.nlm.nih.gov/ pubmed/27741104.

18. Tan ACS, Tan GS, Denniston AK, Keane PA, Ang M, Milea D, et al. An overview of the clinical applications of optical coherence tomography angiography. Eye [Internet]. Nature Publishing Group;
2017 [cited 2018 Aug 10];32:262-86. Available from: https://doi. org/10.1038/eye.2017.181

19. Wang RK, Zhang Q, Li Y, Song S. Optical coherence tomography angiography-based capillary velocimetry. J Biomed Opt [Internet]. 2017;22:066008. Available from. https://doi.org/10.1117/1.JBO. 22.6.066008.

20. Choi J, Kwon J, Shin JW, Lee J, Lee S, Kook MS. Quantitative optical coherence tomography angiography of macular vascular structure and foveal avascular zone in glaucoma. Bhattacharya S, editor. PLoS One [Internet]. Public Library of Science; 2017 [cited 2018 Aug 17];12:e0184948. Available from: https://doi.org/10. 1371/journal.pone. 0184948

21. Akil H, Falavarjani K, Sadda S, Sadun A. Optical coherence tomography angiography of the optic disc; an overview. J Ophthalmic Vis Res [Internet]. 2017;12:98 Available from: http://www.jovr.org/ text.asp?2017/12/1/98/200162.

22. Wylęgała A, Wylęgała F, Wylęgała E. Aflibercept treatment leads to vascular abnormalization of the choroidal neovascularization. J Healthc Eng [Internet]. 2018;2018:1-5 Available from: https:// www.hindawi.com/journals/jhe/2018/8595278/.

23. Holz GRP. Retinale Bildgebung von Makula und Papille. Der Ophthalmol [Internet]. 2017;114:114-6. Available from. https:// doi.org/10.1007/s00347-016-0412-8.

24. Cabrera DeBuc D, Somfai GM, Koller A. Retinal microvascular network alterations: potential biomarkers of cerebrovascular and neural diseases. Am J Physiol - Hear Circ Physiol [Internet]. 2017;312:H201-12. Available from. https://doi.org/10.1152/ ajpheart.00201.2016.

25. Srinivasan VJ, Yu E, Radhakrishnan H, Can A, Climov M, Leahy C, Ayata C, Eikermann-Haerter K Micro-heterogeneity of flow in a mouse model of chronic cerebral hypoperfusion revealed by longitudinal Doppler optical coherence tomography and angiography. J Cereb Blood Flow Metab [Internet]. Nat Publ Group; 2015;1-9. Available from: https://doi.org/10.1038/jcbfm.2015.175

26. Li Y, Choi WJ, Wei W, Song S, Zhang Q, Liu J, et al. Agingassociated changes in cerebral vasculature and blood flow as determined by quantitative optical coherence tomography angiography. Neurobiol Aging. 2018;70:148-59.

27. Mirzaei M, Gupta V, Gupta V. Retinal changes in Alzheimer's disease : disease mechanisms to evaluation perspectives. J Neurol Neuromed. 2018;3:11-3.

28. Pelak VS, Hills W. Vision in Alzheimer's disease: a focus on the anterior afferent pathway. Neurodegener Dis Manag [Internet]. 2018 [cited 2018 Aug 11];8:49-67. Available from: https://doi. org/10.2217/nmt-2017-0030

29. Lesage SR, Mosley TH, Wong TY, Szklo M, Knopman D, Catellier DJ, et al. Retinal microvascular abnormalities and cognitive decline: the ARIC 14-year follow-up study. Neurology [Internet]. 2009 [cited 2018 Sep 24];73:862-8. Available from: http://www. ncbi.nlm.nih.gov/pubmed/19752453.

30. Santos CY, Johnson LN, Sinoff SE, Festa EK, Heindel WC, Snyder PJ. Change in retinal structural anatomy during the preclinical stage of Alzheimer's disease. Alzheimer's Dement Diagnosis, Assess Dis Monit [Internet]. 2018;10:196-209 Available from: http:// linkinghub.elsevier.com/retrieve/pii/S2352872918300034.

31. Ferrari L, Huang SC, Magnani G, Ambrosi A, Comi G, Leocani L. Optical coherence tomography reveals retinal neuroaxonal thinning in frontotemporal dementia as in Alzheimer's disease. J Alzheimer's Dis [Internet]. IOS Press; 2017 [cited 2018 Aug 11];56:1101-7. Available from: https://doi.org/10.3233/JAD160886

32. Snyder PJ, Johnson LN, Lim YY, Santos CY, Alber J, Maruff P, et al. Nonvascular retinal imaging markers of preclinical Alzheimer's disease. Alzheimer's Dement Diagnosis, Assess Dis Monit. 2016;4:169-78. 
33. Santos CY, Johnson LN, Lim YY, Fernandez BM, Ott BR, Salloway $\mathrm{S}$, et al. Retinal nerve fiber layer and ganglion cell layer volume changes in preclinical Alzheimer's disease over 27 months. Alzheimer's Dement [Internet]. Elsevier; 2017 [cited 2018 Aug 13];13:P1280. Available from: https://www.sciencedirect. com/science/article/pii/S1552526017321581

34. Bulut M, Kurtuluș F, Gözkaya O, Erol MK, Cengiz A, Akıdan M, et al. Evaluation of optical coherence tomography angiographic findings in Alzheimer's type dementia. Br J Ophthalmol [Internet]. 2018;102:233-7. https://doi.org/10.1136/bjophthalmol2017-310476 This study reports larger FAZ lower retinal density in patients with AD. All vascular parameters correlated with MMSE.

35. Grewal DS, Polascik BW, Hoffmeyer GC, Fekrat S. Assessment of differences in retinal microvasculature using OCT angiography in Alzheimer's disease: a twin discordance report. Ophthalmic Surg Lasers Imaging Retina [Internet]. 2018 [cited 2018 Jul 15];49:4404. Available from: https://search.proquest.com/openview/ $1 \mathrm{c} 6 \mathrm{df} 89162357 \mathrm{fe} 3 \mathrm{cb} 56 \mathrm{f} 933116 \mathrm{fb} 4 \mathrm{f} 9 / 1$ ? pq-origsite $=$ gscholar\&cbl=13886

36. Jiang H, Wei Y, Shi Y, Wright CB, Sun X, Gregori G, et al. Altered macular microvasculature in mild cognitive impairment and Alzheimer disease. J Neuro-Ophthalmology [Internet]. 2018;38: 292-8 Available from: http://insights.ovid.com/crossref?an= 00041327-201809000-00006.

37. Santos C. Cardiovascular and retinal vascular changes in preclinical Alzheimer's disease [Internet]. Open Access Diss. 2018 [cited 2018 Aug 17]. Available from: https://digitalcommons.uri.edu/oa_diss/ 741

38. Ascaso FJ, Marco S, Mateo J, Martínez M, Esteban O, Grzybowski A. Optical coherence tomography in patients with chronic migraine: literature review and update [Internet]. Front. Neurol. Frontiers Media SA; 2017 [cited 2018 Aug 13]. p. 684. Available from: http://www.ncbi.nlm.nih.gov/pubmed/29321760.

39. Chang MY, Phasukkijwatana N, Garrity S, Pineles SL, Rahimi M, Sarraf D, et al. Foveal and peripapillary vascular decrement in migraine with aura demonstrated by optical coherence tomography angiography. Investig Ophthalmol Vis Sci. 2017;58:5477-84 Migraine with aura contrary to without leads to perifoveal flow decrease. This may explain higher risk of retinal vascular incidence in patients with migraine.

40. Fang X-J, Yu M, Wu Y, Zhang Z-H, Wang W-W, Wang Z-X, et al. Study of enhanced depth imaging optical coherence tomography in cerebral autosomal dominant arteriopathy with subcortical infarcts and leukoencephalopathy. Chin Med J (Engl) [Internet]. 2017;130: 1042 Available from: http://www.cmj.org/text.asp?2017/130/9/ 1042/204935.

41. Falavarjani KG, Tian JJ, Akil H, Garcia GA, Sadda SR, Sadun AA. Swept-source optical coherence tomography angiography of the optic disk in optic neuropathy. Retina [Internet]. 2016 [cited 2018 Aug 17]. p. S168-77. Available from: http://www.ncbi.nlm.nih. gov/pubmed/28005675.

42. Balducci N, Morara M, Veronese C, Barboni P, Casadei NL, Savini $\mathrm{G}$, et al. Optical coherence tomography angiography in acute arteritic and non-arteritic anterior ischemic optic neuropathy. Graefe's Arch Clin Exp Ophthalmol [Internet]. Graefe's Archive for Clinical and Experimental Ophthalmology. 2017;255:225561. Available from. https://doi.org/10.1007/s00417-017-3774-y.

43. Fard MA, Suwan Y, Moghimi S, Geyman LS, Chui TY, Rosen RB, et al. Pattern of peripapillary capillary density loss in ischemic optic neuropathy compared to that in primary open-angle glaucoma. PLoS One [Internet]. Public Library of Science; 2018 [cited 2018 Aug 18];13:e0189237. Available from: http://www.ncbi.nlm.nih. gov/pubmed/29320503.

44. Ling J-W, Yin X, Lu Q-Y, Chen Y-Y, Lu P-R. Optical coherence tomography angiography of optic disc perfusion in non-arteritic anterior ischemic optic neuropathy. Int J Ophthalmol [Internet]. Press of International Journal of Ophthalmology 2017 [cited 2018 Aug 18];10:1402-6. Available from: http://www.ncbi.nlm.nih.gov/ pubmed/28944200.

45. Mastropasqua R, Agnifili L, Borrelli E, Fasanella V, Brescia L, Antonio LD, et al. Optical coherence tomography angiography of the peripapillary retina in normal-tension glaucoma and chronic nonarteritic anterior ischemic optic neuropathy. Curr Eye Res [Internet]. Taylor \& Francis; 2018 [cited 2018 Aug 18];43:77884. Available from: https://doi.org/10.1080/02713683.2018. 1438630

46. Hata M, Oishi A, Muraoka Y, Miyamoto K, Kawai K, Yokota S, et al. Structural and functional analyses in nonarteritic anterior ischemic optic neuropathy. J Neuro-Ophthalmology [Internet]. 2017 [cited 2018 Aug 18];37:140-8. Available from: http://insights.ovid. com/crossref?an $=00041327-201706000-00006$

47. Wang L, Murphy O, Caldito NG, Calabresi PA, Saidha S. Emerging applications of optical coherence tomography angiography (OCTA) in neurological research. Eye Vis [Internet]. Eye and Vision; 2018;5:1-11. Available from: https://doi.org/10.1186/s40662-0180104 Papers/W/Wang et al. 2018 - Emerging Applications of Optical Coherence Tomography Angiograph.

48.• Spain RI, Liu L, Zhang X, Jia Y, Tan O, Bourdette D, et al. Optical coherence tomography angiography enhances the detection of optic nerve damage in multiple sclerosis. Br J Ophthalmol [Internet]. 2018;102:520-4. https://doi.org/10.1136/bjophthalmol-2017310477 The authors report $\mathrm{ONH}$ perfusion loss in patients with MS particularly with eyes with history of optic neuritis. They advocate the use of OCTA to increase the diagnostic accuracy.

49.• Feucht N, Maier M, Lepennetier G, Pettenkofer M, Wetzlmair C, Daltrozzo T, et al. Optical coherence tomography angiography indicates associations of the retinal vascular network and disease activity in multiple sclerosis. Mult Scler J [Internet]. 2018;00:111. https://doi.org/10.1177/1352458517750009 Medium size study of MS patients. Optic neuritis during MS leads to a decrease of retinal vasculature in both the superficial and deep layers.

50. Wingerchuk DM, Banwell B, Bennett JL, Cabre P, Carroll W, Chitnis T, et al. International consensus diagnostic criteria for neuromyelitis optica spectrum disorders. Neurology [Internet]. American Academy of Neurology; 2015 [cited 2018 Oct 6];85: 177-89. Available from: http://www.ncbi.nlm.nih.gov/pubmed/ 26092914

51.• Huang Y, Zhou L, Zhangbao J, Cai T, Wang B, Li X, et al. Peripapillary and parafoveal vascular network assessment by optical coherence tomography angiography in aquaporin-4 antibodypositive neuromyelitis optica spectrum disorders. Br J Ophthalmol [Internet]. 2018 ;bjophthalmol-2018-312231. Available from: https://doi.org/10.1136/bjophthalmol-2018-312231. Retinal vascular abnormalization may occur in NMOSD before the changes are visible in OCT B-scans.

52. Bringmann A, Pannicke T, Grosche J, Francke M, Wiedemann P, Skatchkov S, et al. Müller cells in the healthy and diseased retina. Prog Retin Eye Res [Internet] 2006 [cited 2017 Sep 1];25:397-424. Available from: http://www.ncbi.nlm.nih.gov/pubmed/16839797.

53. Spaide RF, Klancnik JM, Cooney MJ, Yannuzzi LA, Balaratnasingam C, Dansingani KK, et al. Volume-rendering optical coherence tomography angiography of macular telangiectasia type 2. Ophthalmology [Internet]. Elsevier Inc; 2015;122:2261-9. Available from: http://linkinghub.elsevier.com/retrieve/pii/ S0161642015007630

54. Kwapong WR, Peng C, He Z, Zhuang X, Shen M, Lu F. Altered macular microvasculature in neuromyelitis optica spectrum disorders. Am J Ophthalmol [Internet]. 2018;192:47-55 Available from: https://inkinghub.elsevier.com/retrieve/pii/S0002939418302071. 
55. Borrelli E, Balasubramanian S, Triolo G, Barboni P, Sadda SR, Sadun AA. Topographic macular microvascular changes and correlation with visual loss in chronic Leber hereditary optic neuropathy. Am J Ophthalmol [Internet]. 2018;192:217-28 Available from: https:/linkinghub.elsevier.com/retrieve/pii/S0002939418302617.

56. Gaier ED, Gittinger JW, Cestari DM, Miller JB. Peripapillary capillary dilation in leber hereditary optic neuropathy revealed by optical coherence tomographic angiography [Internet]. JAMA Ophthalmol. American Medical Association; 2016 [cited 2018 Aug 10]. p. 1332-4. Available from: https://doi.org/10.1001/ jamaophthalmol.2016.3593

57. Matsuzaki M, Hirami Y, Uyama H, Kurimoto Y. Optical coherence tomography angiography changes in radial peripapillary capillaries in Leber hereditary optic neuropathy. Am J Ophthalmol Case Reports [Internet]. Elsevier; 2018;9:51-5. Available from: https:// doi.org/10.1016/j.ajoc.2018.01.003

58. Jurkute N, Yu-Wai-Man P. Leber hereditary optic neuropathy: bridging the translational gap [Internet]. Curr Opin Ophthalmol. 2017:403-9 Available from: http://insights.ovid.com/crossref?an= 00055735-201709000-00002.

59. Hwang TJ, Karanjia R, Moraes-Filho MN, Gale J, Tran JS, Chu ER, et al. Natural history of conversion of Leber's hereditary optic neuropathy: a prospective case series. Ophthalmology [Internet]. Elsevier; 2017 [cited 2018 Oct 6];124:843-50. Available from: https://www. sciencedirect.com/science/article/pii/S016164201630848X

60. Balducci N, Cascavilla ML, Ciardella A, La Morgia C, Triolo G, Parisi V, et al. Peripapillary vessel density changes in Leber's hereditary optic neuropathy: a new biomarker. Clin Experiment Ophthalmol [Internet]. 2018; Available from: https://doi.org/10. 1111/ceo.13326. Prospective study, 22 patients. LHON patients had lower capillary density, the changes corresponded with the stage of the disease.

61. Borrelli E, Triolo G, Cascavilla ML, La Morgia C, Rizzo G, Savini $\mathrm{G}$, et al. Changes in choroidal thickness follow the RNFL changes in Leber's hereditary optic neuropathy. Sci Rep [Internet]. Nature Publishing Group; 2016 [cited 2018 Oct 6];6:37332. Available from: http://www.ncbi.nlm.nih.gov/pubmed/27853297.

62. Asanad S, Wu J, Nassisi M, Ross-Cisneros FN, Sadun AA. Optical coherence tomography-angiography in Wolfram syndrome: a mitochondrial etiology in disease pathophysiology. Can J Ophthalmol [Internet]. 2018; Available from: http://linkinghub.elsevier.com/ retrieve/pii/S0008418218301625

63.• Parrozzani R, Leonardi F, Frizziero L, Trevisson E, Clementi M, Pilotto E, et al. Retinal vascular and neural remodeling secondary to optic nerve axonal degeneration. Ophthalmol Retin [Internet]. Elsevier; 2018 [cited 2018 May 24];2:827-35. Available from: https://www.sciencedirect.com/science/article/pii/ S2468653017306449\#. The authors report remodeling of the neuroretina due to optic pathway glioma and vascular alterations involving both the peripapillary area and perifoveal zone.

64. Kawasaki R, Che Azemin MZ, Kumar DK, Tan AG, Liew G, Wong TY, et al. Fractal dimension of the retinal vasculature and risk of stroke: a nested case-control study. Neurology [Internet]. Wolters Kluwer Health, Inc. on behalf of the American Academy of Neurology; 2011 [cited 2018 Aug 11];76:1766-7. Available from: http:/www.ncbi.nlm.nih.gov/pubmed/21576694.

65. Lindley RI, Wang JJ, Wong MC, Mitchell P, Liew G, Hand P, et al. Retinal microvasculature in acute lacunar stroke: a cross-sectional study. Lancet Neurol. 2009;8:628-34.

66. Patton N, Pattie A, MacGillivray T, Aslam T, Dhillon B, Gow A, et al. The association between retinal vascular network geometry and cognitive ability in an elderly population. Investig Ophthalmol Vis Sci [Internet]. The Association for Research in Vision and Ophthalmology; 2007 [cited 2018 Aug 11];48:1995-2000. Available from: https://doi.org/10.1167/iovs.06-1123
67. Ding J, Strachan MWJ, Fowkes FGR, Wong TY, MacGillivray TJ, Patton N, et al. Association of retinal arteriolar dilatation with lower verbal memory: the Edinburgh type 2 diabetes study. Diabetologia. 2011;54:1653-62.

68. Bernucci MT, Merkle CW, Srinivasan VJ. Investigation of artifacts in retinal and choroidal OCT angiography with a contrast agent. Biomed Opt Express [Internet]. 2018;9:1020 Available from: https://www.osapublishing.org/abstract.cfm?URI=boe-9-3-1020.

69. Garcia GA, Tian JJJJ, Apinyawasisuk S, Kim S, Akil H, Sadun, AAAA. Clues from Crouzon: insights into the potential role of growth factors in the pathogenesis of myelinated retinal nerve fibers. J Curr Ophthalmol [Internet]. Elsevier; 2016 [cited 2018 Aug 17];28:232-6. Available from: https://www.sciencedirect. com/science/article/pii/S2452232516301299?via\%3Dihub

70. Wright Mayes E, Cole ED, Dang S, Novais EA, Vuong L, MendozaSantiesteban C, et al. Optical coherence tomography angiography in nonarteritic anterior ischemic optic neuropathy. J NeuroOphthalmology [Internet]. 2017 [cited 2018 Aug 20];37:358-64. Available from: http:/www.ncbi.nlm.nih.gov/pubmed/28301863.

71. Mastropasqua R, Borrelli E, Agnifili L, Toto L, Di Antonio L, Senatore A, et al. Radial peripapillary capillary network in patients with retinitis pigmentosa: an optical coherence tomography angiography study. Front Neurol. 2017;8:3-7.

72. Balducci N, Morara M, Veronese C, Barboni P, Casadei NL, Savini $\mathrm{G}$, et al. Optical coherence tomography angiography in acute arteritic and non-arteritic anterior ischemic optic neuropathy. Graefe's Arch Clin Exp Ophthalmol [Internet]. Springer Berlin Heidelberg; 2017 [cited 2018 Aug 18];255:2255-61. Available from: https://doi.org/10.1007/s00417-017-3774-y

73. Di G, Weihong Y, Xiao Z, Zhikun Y, Xuan Z, Yi Q, et al. A morphological study of the foveal avascular zone in patients with diabetes mellitus using optical coherence tomography angiography. Graefe's Arch Clin Exp Ophthalmol [Internet]. 2016 [cited 2017 Aug 27];254:873-9. Available from: http://www.ncbi.nlm.nih.gov/ pubmed/26344729.

74. Mastropasqua R, Di Antonio L, Di Staso S, Agnifili L, Di Gregorio A, Ciancaglini M, et al. Optical coherence tomography angiography in retinal vascular diseases and choroidal neovascularization. J Ophthalmol [Internet]. Hindawi Publishing Corporation; 2015;2015:1-8. Available from: http://www.hindawi.com/ journals/joph/2015/343515/

75. Yun C, Ahn J, Kim M, Kim JT, Hwang S-Y, Kim S-W, et al. Characteristics of retinal vessels in surgically closed macular hole: an optical coherence tomography angiography study. Graefe's Arch Clin Exp Ophthalmol [Internet]. 2017 [cited 2017 Sep 1]; Available from: http://www.ncbi.nlm.nih.gov/pubmed/28744658.

76. Cabrera DeBuc D, Somfai GM, Koller A. Retinal microvascular network alterations: potential biomarkers of cerebrovascular and neural diseases. Am J Physiol - Hear Circ Physiol [Internet]. American Physiological Society; 2017 [cited 2018 Jun 6];312: H201-12. Available from: http://www.ncbi.nlm.nih.gov/pubmed/ 27923786.

77. Rebhun CB, Moult EM, Ploner SB, Neto CM, Alibhai AY, Schottenhamml J, et al. Analyzing relative blood flow speeds in choroidal neovascularization using variable interscan time analysis OCT angiography. Ophthalmol Retin [Internet]. Elsevier; 2017 [cited 2018 9];2:306-19. Available from: https://www.sciencedirect. com/science/article/pii/S2468653017303561\#bib8

78. Salz DA, Carlo T de, Adhi M, Moult E, Choi WJ, Baumal CR, et al. Prototype ultra-high speed swept source optical coherence tomography angiography compared with intravenous fluorescein angiography in diabetic retinopathy. Invest Ophthalmol Vis Sci [Internet]. The Association for Research in Vision and Ophthalmology; 2015 [cited 2015 Dec 5];56:3341. Available from: http://iovs. arvojournals.org/article.aspx?articleID=2333199 
79. Roisman L, Zhang Q, Wang RK, Gregori G, Zhang A, Chen C-L, et al. Optical coherence tomography angiography of asymptomatic neovascularization in intermediate age-related macular degeneration. Ophthalmology [Internet]. American Academy of Ophthalmology. 2016;123:1-11 Available from: http://inkinghub. elsevier.com/retrieve/pii/S0161642016001500.

80. Legarreta AD, Durbin MK, An LIN, Sharma U, Stetson PF, Legarreta JE, et al. Swept source optical coherence of neovascular macular telangiectasia type 2. 2015;

81. Werner JS, Burns SA, Merigan WH, Artal P, Atchison DA, Hampson KM, et al. Vision science and adaptive optics, the state of the field. Vision Res [Internet]. Pergamon; 2017 [cited 2018 Aug 20];132:3-33. Available from: https://www.sciencedirect. com/science/article/pii/S0042698917300238

82. Salas M, Augustin M, Ginner L, Kumar A, Baumann B, Leitgeb R, et al. Visualization of micro-capillaries using optical coherence tomography angiography with and without adaptive optics. Biomed Opt Express [Internet]. Optical Society of America; 2017 [cited 2018 Aug 13];8:11438-52. Available from: https://www. osapublishing.org/abstract.cfm?URI=boe-8-1-207

83. Lee MJ, Abraham AG, Swenor BK, Sharrett AR, Ramulu PY. Application of optical coherence tomography in the detection and classification of cognitive decline. Dada T, Shaarawy T, editors. J Curr Glaucoma Pract with DVD [Internet]. 2018;12:10-8. Available from: http:/www.jaypeejournals.com/eJournals/
ShowText.aspx $?$ ID $=13617 \&$ Type $=$ FREE $\&$ TYP $=$ TOP $\& I N=$ $\sim /$ Journals/images/JPLOGO.gif\&IID=1062\&isPDF=YES

84. Cunha-Vaz J, Santos T, Alves D, Marques I, Neves C, Soares M, et al. Agreement between OCT leakage and fluorescein angiography to identify sites of alteration of the blood-retinal barrier in diabetes. Ophthalmol Retin [Internet]. Elsevier; 2017 [cited 2018 Jun 16];1:395-403. Available from: http://linkinghub.elsevier.com/ retrieve/pii/S2468653017300465

85. Told R, Sacu S, Hecht A, Baratsits M, Eibenberger K, Kroh ME, et al. Comparison of SD-optical coherence tomography angiography and indocyanine green angiography in type 1 and 2 neovascular age-related macular degeneration. Investig Opthalmology Vis Sci [Internet]. The Association for Research in Vision and Ophthalmology; 2018 [cited 2018 Aug 13];59:2393. Available from: https://doi.org/10.1167/iovs.17-22902

86. Opara JA, Brola W, Wylegała Adam WE. Uhthoff's phenomenon 125 years later - what do we know today?. J Med Life [Internet]. 2016;9. Available from: http://www.medandlife.ro/archive/284vol-ix-iss-1-january-march-2016/special-articles-vol-viii-iss-3/726uhthoff-s-phenomenon-125-years-later-what-do-we-know-today

87. Schönfeldt-Lecuona C, Kregel T, Schmidt A, Pinkhardt EH, Lauda F, Kassubek J, et al. From imaging the brain to imaging the retina: optical coherence tomography (oct) in schizophrenia. Schizophr Bull [Internet]. Oxford University Press; 2015 [cited 2018 Aug 21];42:sbv073. Available from: https://doi.org/10.1093/ schbul/sbv073 